\title{
Sucessão entre cultivos orgânicos de milho e couve consorciados com leguminosas em plantio direto
}

\author{
Edmilson E Silva'; Helvécio De-Polli²; José Guilherme M Guerra²; Elen L Aguiar-Menezes²; André Luis S \\ Resende $^{2}$; Fábio Luiz de Oliveira ${ }^{3}$; Raul de LD Ribeiro ${ }^{4}$ \\ ${ }^{1}$ Embrapa Roraima, C. Postal 133, 69301-970 Boa Vista-RR; ${ }^{2}$ Embrapa Agrobiologia, C. Postal 74505, 23890-000 Seropédica-RJ; \\ ${ }^{3}$ UFVJM, R. da Glória, 187, 39100-000 Diamantina-MG; ${ }^{4}$ UFRRJ-Inst. de Agronomia, BR 465, km 07, 23851-970 Seropédica-RJ; \\ edmilson@cpafrr.embrapa.br
}

\section{RESUMO}

Práticas agrícolas têm sido desenvolvidas para reduzir a aplicação de insumos químicos e minimizar as agressões ao meio ambiente, produzindo alimentos mais saudáveis e ecologicamente corretos. Portanto, o objetivo deste trabalho foi avaliar o desempenho da sucessão entre couve (Brassica oleracea L. var. acephala) e milho (Zea may L.), em consórcio com leguminosas para fins de adubação verde, sob plantio direto em manejo orgânico. O estudo foi conduzido em Seropédica, Região metropolitana do Rio de Janeiro, em dois anos. Utilizaram-se, como adubos verdes, mucuna-anã (Mucuna deeringiana) e crotalária spectabilis (Crotalaria spectabilis) em consórcio com couve e em sucessão crotalária juncea (Crotalaria juncea) e mucuna-cinza (Mucuna pruriens) em consórcio com milho. Como controles utilizaram-se os monocultivos de couve e milho. $\mathrm{O}$ delineamento foi em blocos ao acaso, constituindo fatorial 3 (sistema de cultivo) x 2 (doses de cama-de-frango), com quatro repetições, em parcelas de $20 \mathrm{~m}^{2}$. Na couve, aplicou-se em cobertura cama-defrango nas doses 0 e 5,4 t ha-1 $\left(2,7 \mathrm{t} \mathrm{ha}^{-1}\right.$ em duas aplicações) em 2003 e 0 e $2,7 \mathrm{t} \mathrm{ha}^{-1}$ em 2004. Em monocultivo, a produtividade da couve foi de 37,7 e 18,4 tha ${ }^{-1}$; consorciada com mucuna-anã, foi de 40,3 e $38,8 \mathrm{t} \mathrm{ha}^{-1}$ e com crotalária spectabilis, de 42,9 e $24,8 \mathrm{t} \mathrm{ha}^{-1}$, em 2003 e 2004, respectivamente. O milho beneficiou-se do efeito residual da adubação com cama-de-frango, aumentando o número de espigas produzidas de 25.625 para $27.916 \mathrm{ha}^{-1}$. O cultivo de couve em sucessão ao milho, consorciada com leguminosas anuais, sob adubação orgânica com cama-de-frango, resultou em aumento de produtividade das culturas de couve e milho.

Palavras-chave: Brassica oleracea L. var. acephala, Zea mays L., Crotalaria spp., Mucuna spp., agricultura orgânica.
ABSTRACT

Organic crop succession of maize and collard greens intercropped with legumes in no-tillage system

New farming practices have been developed to reduce the application of fertilizer and pesticides and minimize the aggression to the environment, producing healthy foods and environmentally correct. We evaluated the performance of the succession of collard greens (Brassica oleracea L. var. acephala) and corn (Zea mays L.) intercropped with green manure legumes under no-tillage organic system. The study was conducted in Seropédica, Rio de Janeiro State, during two years. We utilized dwarf velvet bean (Mucuna deeringiana) and showy crotalaria (Crotalaria spectabilis) as green manure intercropped with collard greens and in succession sunn hemp (Crotalaria juncea) and velvet bean (Mucuna pruriens) intercropped with corn. As a control, there was a single crop system of corn and collard greens. The experimental design was of randomized complete blocks, a factorial 3 (crop system) x 2 (doses of poultry bed manure), with four replications, in plots of $20 \mathrm{~m}^{2}$. For the collard greens we applied 0 and $5.4 \mathrm{tha}^{-1}$ of poultry bed manure $\left(2.7 \mathrm{t} \mathrm{ha}^{-1}\right.$ in two applications) in 2003; 0 (zero) and $2.7 \mathrm{t} \mathrm{ha}^{-1}$ in 2004. In the monocrop system, the yield of collard greens was of 37.7 and 18.4 $\mathrm{t} \mathrm{ha}^{-1}$, intercropped with dwarf velvet bean the yield reached 40.3 and $38.8 \mathrm{tha}^{-1}$ and, using showy crotalaria the yield was of 42.9 and 24.8 $\mathrm{t} \mathrm{ha}^{-1}$, in 2003 and 2004, respectively. The corn was benefited from the residual effect of fertilizer with poultry bed manure increasing the production of ears from 25,625 to $27,916 \mathrm{ha}^{-1}$. Crop succession of collard greens and corn, intercropped with annual legumes under organic fertilization as poultry bed manure, showed yield increase for collard greens and corn.

Keywords: Brassica oleracea L. var. acephala, Zea mays L., Crotalaria spp., Mucuna spp., organic agriculture.

(Recebido para publicação em 1 de dezembro de 2008; aceito em 18 de janeiro de 2011) (Received on December 1, 2008; accepted on January 18, 2011)

$\mathrm{O}$ uso da adubação verde nas unidades de produção orgânica é uma estratégia importante com elevado potencial de impacto na produtividade das culturas e na conservação do solo. $\mathrm{O}$ uso de espécies de leguminosas, notadamente em áreas passíveis de pousio, tem sido preconizado como alternativa interessante para o suprimento de nitrogênio às culturas (Espindola et al., 2006). A adubação verde acrescenta nitrogênio e outros nutrientes ao agroecossistema (Silva et al., 2009), proporciona adequada cobertura do solo, reduzindo riscos de erosão, atenua a competição das plantas espontâneas com as culturas, contribuindo, ademais, para a biodiversidade funcional nas unidades de produção (Oliveira et al., 2003).

Pesquisas sobre o consórcio simul- tâneo ou rotativo de adubos verdes com hortaliças são ainda restritas no Brasil. Em experimento buscando avaliar o efeito da adubação verde residual no rendimento de brócolos na sucessão crotalária/milho/brócolos, verificou-se aumento no teor de $\mathrm{N}$ acumulado nas folhas e inflorescências do brócolos, apesar do aproveitamento após a sucessão ter sido baixo (Perin et al., 2004). Em 
outro trabalho buscando avaliar o efeito do cultivo de milho consorciado com feijão-de-porco, não foram observados aumentos significativos na produção de milho tanto para consumo de espigas imaturas quanto para produção de grãos (Perin et al., 2007).

Nos últimos anos, o sistema de plantio direto vem sendo apontado como uma estratégia capaz de contribuir para a sustentabilidade da exploração agrícola, porque dentre outros, aumenta a quantidade de microrganismos do solo. Entretanto, sua atividade metabólica nesse sistema é baixa, se comparada ao convencional, indicando maior eficiência metabólica da microbiota do solo (Pereira et al., 2007). Para cereais e oleaginosas, por exemplo, a técnica já se encontra disseminada no Brasil; porém, quanto às hortaliças, o plantio direto precisa ser adaptado, sendo escassa a literatura nacional a respeito (Pontes, 2001).

A sucessão de culturas apresenta aspectos interessantes como exploração e aporte de matéria orgânica diferenciada ao solo pelo sistema radicular, condições para o desenvolvimento de predadores, alternância de exploração de nutrientes e água, redução nos níveis de compactação do solo e oferta diferenciada de produtos ao mercado (Wutke et al., 2003).

O objetivo deste trabalho foi avaliar a sucessão entre as culturas de milho (Zea mays L.) para colheita de espigas imaturas e couve (Brassica oleracea L. var. acephala), cada qual em consórcio simultâneo com diferentes espécies de leguminosas para fins de adubação verde, sob plantio direto e manejo orgânico.

\section{MATERIAL E MÉTODOS}

O estudo foi conduzido no Sistema Integrado de Produção Agroecológica (SIPA), nos anos de 2003 e 2004. O SIPA representa um espaço destinado ao exercício da Agroecologia, localizado no município de Seropédica, Região Metropolitana do Estado do Rio de Janeiro $\left(22^{\circ} 45^{\prime} \mathrm{S}, 43^{\circ} 41^{\prime} \mathrm{W}, 33 \mathrm{~m}\right.$ de altitude), sendo o clima local incluído na classificação de Köppen como do tipo Aw (Peel et al., 2007). A tempe- ratura média das máximas anuais é de $29,8^{\circ} \mathrm{C}$ e das mínimas, de $20,1^{\circ} \mathrm{C}$, com precipitação média dos últimos 20 anos de $1281 \mathrm{~mm}$.

O solo da área experimental foi classificado como Argissolo VermelhoAmarelo (Embrapa, 1999), sendo rotineiramente cultivado com hortaliças, apresentando os seguintes valores para a análise de fertilidade na camada de 0 a $10 \mathrm{~cm}: \mathrm{pH}=6,8 ; \mathrm{Ca}=3,8 \mathrm{cmol}_{\mathrm{c}} \mathrm{dm}^{-3}$; $\mathrm{Mg}=1,5 \mathrm{cmol}_{\mathrm{c}} \mathrm{dm}^{-3} ; \mathrm{P}=136 \mathrm{mg} \mathrm{dm}^{-3}$; $\mathrm{K}=170 \mathrm{mg} \mathrm{dm}^{-3}$; na camada de 10 a 20 cm: $\mathrm{pH}=6,8 ; \mathrm{Ca}=3,3 \mathrm{cmol} \mathrm{dm}^{-3} ; \mathrm{Mg}=$ $1,4 \mathrm{cmol}_{\mathrm{c}} \mathrm{dm}^{-3} ; \mathrm{P}=95 \mathrm{mg} \mathrm{dm}^{-3} ; \mathrm{K}=75$ mg dm${ }^{-3}$; camada de 20 a $30 \mathrm{~cm}: \mathrm{pH}=$ 6,8; $\mathrm{Ca}=3,2 \mathrm{cmol}_{\mathrm{c}} \mathrm{dm}^{-3} ; \mathrm{Mg}=1,0 \mathrm{cmol}_{\mathrm{c}}$ $\mathrm{dm}^{-3} ; \mathrm{P}=90 \mathrm{mg} \mathrm{dm}^{-3} ; \mathrm{K}=205 \mathrm{mg} \mathrm{dm}^{-3}$, com ausência de alumínio em solução para as três profundidades analisadas. Foi utilizada a cultivar de couve HS20 (Horticeres) e de milho, a cultivar Eldorado.

As leguminosas utilizadas no consórcio foram mucuna-cinza (Mucuna pruriens), de hábito volúvel; mucuna-anã (Mucuna deeringiana), de crescimento determinado; crotalária spectabilis (Crotalaria spectabilis), de porte subarbustivo; e crotalária juncea (Crotalaria juncea), de porte arbustivo. Mucuna-anã e crotalária spectabilis foram consorciadas com a couve, enquanto mucuna-cinza e crotalária juncea foram semeadas nas entrelinhas do milho.

No esquema de sucessão adotado foi primeiramente implantada a cultura da couve, em junho de 2003. Os tratamentos constaram de couve em monocultivo, couve consorciada com mucuna-anã e couve consorciada com crotalária spectabilis, sem ou com camade-frango em cobertura. Os tratamentos foram arranjados em fatorial $3 \times 2$, no delineamento de blocos ao acaso, com quatro repetições. A cama-de-frango foi parcelada em duas aplicações $\left(6^{\mathrm{a}}\right.$ e $16^{\mathrm{a}}$ colheitas de couve empregando $2,7 \mathrm{tha}^{-1}$ de cama-de-frango em cada aplicação) no primeiro ano e 0 (zero) e $2,7 \mathrm{t} \mathrm{ha}^{-1}$ (dose única na $10^{\mathrm{a}}$ colheita de couve) no segundo ano de cultivo, na mesma área. A cama-de-frango possuía a seguinte composição química: 36,$6 ; 51,5 ; 5,5$; 23,11; 22,0 $\mathrm{g} \mathrm{kg}^{-1}$ de N, Ca, Mg, P e K respectivamente.
As mudas de couve foram produzidas em casa-de-vegetação, em bandejas de poliestireno expandido contendo 128 plantágios, abastecidas com substrato orgânico preparado no próprio SIPA. Não foram realizadas análises químicas do substrato. As mudas de couve foram transplantadas 20 dias após o plantio.

A parcela experimental, para ambos os anos, continha cinco linhas de plantio, com 4,0 m de comprimento, no espaçamento de 1,0 x 0,5 m (20.000 plantas $\mathrm{ha}^{-1}$ ) entre linhas e plantas, respectivamente. Aárea útil foi composta pelas três linhas centrais, descartando-se as primeiras e últimas plantas de cada linha, totalizando 18 indivíduos amostrados. Os adubos verdes foram semeados no dia do transplantio das mudas de couve, ocupando as entrelinhas de forma alternada. A semeadura de crotalária spectabilis foi efetuada em duas fileiras afastadas $0,25 \mathrm{~m}$ da couve e $0,50 \mathrm{~m}$ entre si, na densidade de 30 sementes $\mathrm{m}^{-1}$ (300.000 plantas $\left.\mathrm{ha}^{-1}\right)$, enquanto a mucuna-anã teve densidade de quinze sementes $\mathrm{m}^{-1}$ (150.000 plantas $\left.\mathrm{ha}^{-1}\right)$. Imediatamente antes do transplantio da couve, foi feita aplicação uniforme em todas as covas de esterco bovino curtido, na dose de 6,6 t ha-1, em ambos os anos de experimentação. O esterco bovino apresentava a seguinte composição química: 36,$6 ; 51,5 ; 5,5 ; 23,11 ; 22,0$ $\mathrm{g} \mathrm{kg}^{-1}$ de $\mathrm{N}, \mathrm{Ca}, \mathrm{Mg}, \mathrm{P}$ e K respectivamente. A colheita da couve teve início 20 dias após o transplantio, continuando ininterruptamente por 21 semanas em cada ano de cultivo. Foram analisados o número total de folhas colhidas e a produção comercial em massa fresca, ou seja, as folhas sadias e livres de injurias. As leguminosas foram cortadas na época do florescimento $\left(16^{\mathrm{a}}\right.$ e $18^{\mathrm{a}}$ colheita da couve para 2003 e 2004, respectivamente), sendo o material deixando sobre o solo. Foi determinada a massa aérea fresca por ocasião do corte, sendo subamostras posteriormente transferidas para estufa a $65^{\circ} \mathrm{C}$, onde permaneceram até atingir massa constante para aferição da massa seca.

Após o primeiro ciclo da couve, em dezembro de 2003, foi semeado o milho para colheita de espigas no estado imaturo (verde). Os tratamentos foram arranjados em fatorial $3 \times 2$, no delinea- 
mento de blocos ao acaso, com quatro repetições. A parcela foi constituída de cinco linhas com 4,0 m de comprimento, espaçadas entre elas de 1,0 m e, na linha, de $0,25 \mathrm{~m}$, totalizando 40.000 plantas $\mathrm{ha}^{-1}$. As parcelas onde se encontravam mucuna-anã e crotalária spectabilis foram ocupadas com mucuna-cinza e crotalária juncea, respectivamente. Não foram realizadas adubações no semeio e em cobertura, mas foi considerado em termos de estudo, o efeito residual da adubação realizada na couve. A crotalária juncea foi semeada simultaneamente ao milho, constituindo duas fileiras nas entrelinhas, com doze sementes $\mathrm{m}^{-1}$ (240.000 plantas ha-1). Cada uma dessas fileiras ficou a $0,25 \mathrm{~m}$ das plantas de milho, mantendo entre si $0,5 \mathrm{~m}$ de distância. $\mathrm{O}$ espaçamento da mucuna-cinza foi o mesmo, porém a semeadura ocorreu 50 dias após a do milho, conservando-se apenas cinco plantas $\mathrm{m}^{-1}$. Avaliaram-se a massa fresca e número de espigas colhidas. A colheita do milho foi realizada em fevereiro de 2004, permanecendo a área em descanso pelos três meses seguintes.

Os cultivos foram realizados no sistema plantio direto, usando-se apenas a enxada no preparo dos sulcos de semeadura para o milho, ou no caso da couve, da cova de plantio. Em cada cultivo anual de couve ou de milho, foram precedidas três roçadas da vegetação espontânea, com auxílio de roçadeira costal, nas entrelinhas que não continham os adubos verdes. Foram realizadas capinas com enxada, nas linhas de plantio de couve e milho, sempre que necessárias.

Após o cultivo de milho, em junho de 2004, foi novamente restabelecida a cultura da couve, fechando o ciclo de sucessão em dezembro do mesmo ano, usando o delineamento experimental e as características analisadas como descrito no primeiro experimento. As culturas de milho e couve foram irrigadas por aspersão, segundo suas necessidades hídricas, e pulverizadas semanalmente com produto comercial à base de Bacillus thuringiensis para o controle de lagartas.

As análises estatísticas foram feitas com auxílio do programa estatístico SAEG versão 8.0 (2001), aplicando-se o teste $\mathrm{F}$ para aferição de diferenças entre tratamentos. Constatada significância, as médias foram comparadas pelo teste de Tukey e Scott-Knott ao nível de 5\% de probabilidade.

\section{RESULTADOS E DISCUSSÃO}

As leguminosas aportaram as seguintes quantidades de massa aérea seca ao agroecossistema: crotalária spectabilis - 1,6 tha-1 e mucuna-anã - 1,8 $\mathrm{t} \mathrm{ha}^{-1}$ no primeiro ano; crotalária spectabilis - 1,4 t ha-1 e mucuna-anã - 1,5 t ha ${ }^{-1}$ no segundo ano de consórcio com a couve; crotalária juncea - 2,8 $\mathrm{t} \mathrm{ha}^{-1}$ e mucunacinza - 5,6 t ha-1 no cultivo consorciado com o milho. As leguminosas que estavam em consórcio possuíam altura similar as plantas de couve ou milho, não sendo observada competição entre as culturas por luminosidade.

Não houve interação significativa entre os sistemas de cultivo e a cama-defrango para as características avaliadas. O número de folhas comercializáveis de couve, na presença da crotalária spectabilis, foi superior ao do monocultivo. No consórcio com mucuna-anã, esse efeito positivo relacionou-se à $8^{\mathrm{a}}$ e à $9^{\mathrm{a}}$ colheitas, no primeiro ano (Figura 1A), e a $8^{\text {a }}$ até a $21^{\text {a }}$ colheitas, excluindo-se a $14^{\mathrm{a}}$, no segundo ano (Figura 1B). O efeito do pré-cultivo do milho com mucuna cinza proporcionou, nas parcelas onde a couve estava consorciada com mucuna-anã, as maiores médias de produtividade de couve, demonstrando efeito residual significativo advindo do cultivo anterior de milho. No primeiro ano de experimentação, não houve influência do corte dos adubos verdes em consórcio com a couve. Isto significa que o efeito benéfico originário de crotalária spectabilis ocorreu enquanto esta leguminosa se encontrava vegetando junto à couve e não após sua roçada, pois

Tabela 1. Produtividade e número de folhas de couve e de espigas de milho comercializáveis, nos anos 2003 e 2004, sob manejo orgânico e sistema plantio direto, em monocultivo e consorciados com adubos verdes (marketable yield and leaves number of collard greens and ear of corn under organic management and no-tillage system, in monoculture or intercropped with green manure legumes). Seropédica, Embrapa Agrobiologia, 2003/2004.

\begin{tabular}{|c|c|c|c|c|c|c|}
\hline \multirow{3}{*}{ Sistema de cultivo } & \multicolumn{4}{|c|}{ Couve } & \multicolumn{2}{|c|}{ Milho } \\
\hline & \multicolumn{2}{|c|}{$\mathbf{N}^{0}$ folhas ha $\mathbf{h}^{-1}\left(\mathbf{x} \mathbf{1 0}^{3}\right)$} & \multicolumn{2}{|c|}{$\begin{array}{c}\text { Produtividade } \\
\text { (t ha-1) }\end{array}$} & $\begin{array}{l}\text { Produtividade } \\
\text { (t ha-1) }\end{array}$ & $\mathrm{N}^{\circ}$ espigas ha $\mathbf{a}^{-1}$ \\
\hline & 2003 & 2004 & 2003 & 2004 & 2003 & 2004 \\
\hline Monocultivo & $1.477 \mathrm{a}^{1}$ & $1.183 \mathrm{~b}$ & $37,60 \mathrm{a}$ & $18,40 \mathrm{c}$ & $3,72 \mathrm{a}$ & $25.729 \mathrm{a}$ \\
\hline Mucuna-anã/cinza & $1.445 \mathrm{a}$ & $1.384 \mathrm{a}$ & $40,30 \mathrm{a}$ & $38,80 \mathrm{a}$ & $3,76 \mathrm{a}$ & $27.083 \mathrm{a}$ \\
\hline Crotalária spectabilis/juncea & $1.518 \mathrm{a}$ & $1.244 \mathrm{~b}$ & $43,00 \mathrm{a}$ & $24,80 \mathrm{~b}$ & $4,70 \mathrm{a}$ & $27.499 \mathrm{a}$ \\
\hline \multicolumn{7}{|l|}{ Doses de cama-de-frango } \\
\hline $0 \mathrm{~kg} \mathrm{ha}^{-1}$ & $1.389 \mathrm{~b}$ & $1.235 \mathrm{~b}$ & $40,30 \mathrm{~b}$ & $23,00 \mathrm{~b}$ & $3,26 \mathrm{a}$ & $25.625 \mathrm{~b}$ \\
\hline $2,7 \mathrm{t} \mathrm{ha}^{-1}$ & $--^{2}$ & $1.305 \mathrm{a}$ & - & $31,70 \mathrm{a}$ & - & - \\
\hline $5,4 \mathrm{t} \mathrm{ha}^{-1}$ & $1.571 \mathrm{a}$ & - & $50,40 \mathrm{a}$ & - & $4,08 \mathrm{a}$ & $27.916 \mathrm{a}$ \\
\hline $\mathrm{CV}(\%)$ & 4,72 & 5,51 & 7,93 & 10,78 & 24,3 & 5,7 \\
\hline
\end{tabular}

${ }^{1}$ Médias seguidas da mesma letra nas colunas para sistemas de cultivo e doses de cama-de-frango não diferem entre si (Scott Knott $\left.\mathrm{p}<0,05\right)$; ${ }^{2}$ Não foi efetuada adubação para o referido ano ( ${ }^{1}$ means followed by the same letter in columns for crop systems and doses of poultry bed manure, do not differ (Scott Knott $\mathrm{p}<0.05$ ); ${ }^{2}$ not realized fertilization for the cited years). 


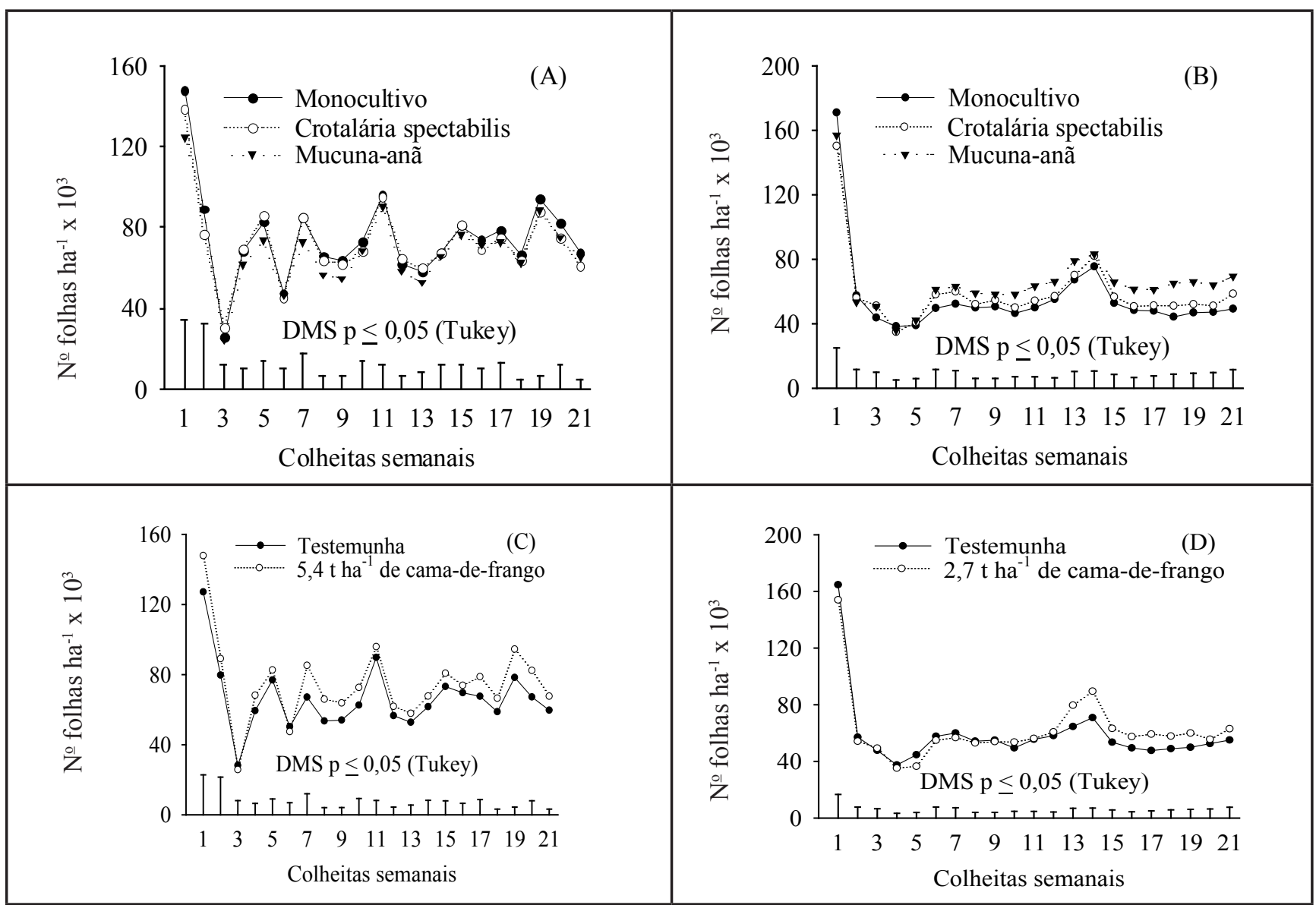

Figura 1. Número de folhas comercializáveis de couve em monocultivo ou consorciada com crotalária spectabilis ou mucuna-anã nos anos 2003 (A) e 2004 (B) e sob aplicação de cama-de-frango nas doses de 0 e 5,4 t ha-1 no ano 2003 (C) e 0 e 2,7 t ha ${ }^{-1}$ em 2004 (D) (marketable leaves number of collard greens in monoculture or intercropped with showy crotalaria or dwarf velvet bean in 2003 (A) and 2004 (B) and under applications with poultry bed manure in the dose of 0 and $5.4 \mathrm{t} \mathrm{ha}^{-1}$ in the year 2003 (C) and 0 and $2.7 \mathrm{t} \mathrm{ha}^{-1}$ in 2004 (D)). Seropédica, Embrapa Agrobiologia, 2003/2004.

tanto a produtividade quanto o número de folhas já possuíam valores superiores em algumas colheitas antes da retirada do consórcio. No segundo ano, não se observou competição das leguminosas com a cultura principal. Entretanto, os ganhos verificados quanto à produtividade da couve foram principalmente originários do pré-cultivo, embora não se possa desconsiderar a participação dos adubos verdes simultaneamente consorciados.

Em relação à produtividade por colheita no primeiro ano (Figura 2A), notou-se que após a parcela inicial de adubação com a cama-de-frango, assim como após a roçada das leguminosas ocorreram respostas positivas, provavelmente, por causa da rápida disponibilização de nutrientes. Contudo, no segundo ano de cultivo da couve (Figura 2B), não houve ganho significativo de produtividade do corte dos consórcios, o que poderia ser atribuído ao efeito supressivo dos pré-cultivos, devido à elevada quantidade de massa depositada no solo. A produtividade foi significativamente superior à do monocultivo, em todas as colheitas, nas parcelas antes ocupadas pela crotalária juncea para a maioria das colheitas e mucuna-cinza, com exceção da $4^{\mathrm{a}}$ colheita, que possuía valores semelhantes ao monocultivo, provavelmente por encontrar-se no final do período posterior ao transplantio. Contribuições dos pré-cultivos de mucuna-cinza e de crotalária juncea, quanto à produtividade da couve, são verificadas do início ao fim dos ciclos de colheita, sempre superiores ao monocultivo, com exceção para $4^{\mathrm{a}}$ colheita (Figura 2B).

Resultados semelhantes foram obtidos avaliando o desempenho do milho e brócolos em sucessão à adubação verde (Perin et al., 2004), comprovando-se a transferência de nitrogênio para o milho, a partir do pré-cultivo de crotalária juncea + milheto, acarretando aumentos no rendimento em grãos e no acúmulo de massa seca da parte aérea. Em consórcios de milho com mucuna-preta (Mucuna aterrima) e feijão-de-porco (Canavalia ensiformis), não foi detectada competição prejudicial (Oliveira et al., 2003); entretanto, os autores ressaltam que certos critérios devem ser respeitados quanto ao modelo espacial e temporal a ser adotado para inclusão das leguminosas.

Quando em cultivo consorciado com crotalária juncea foi verificado aumento de produtividade do pimentão (Cesar et al., 2007). Em outro trabalho com a mesma leguminosa, Oliveira et al. (2007) observaram efeito positivo na produtividade e na redução de queima foliar provocada pela radiação solar em cultura de taro. De modo análogo, 


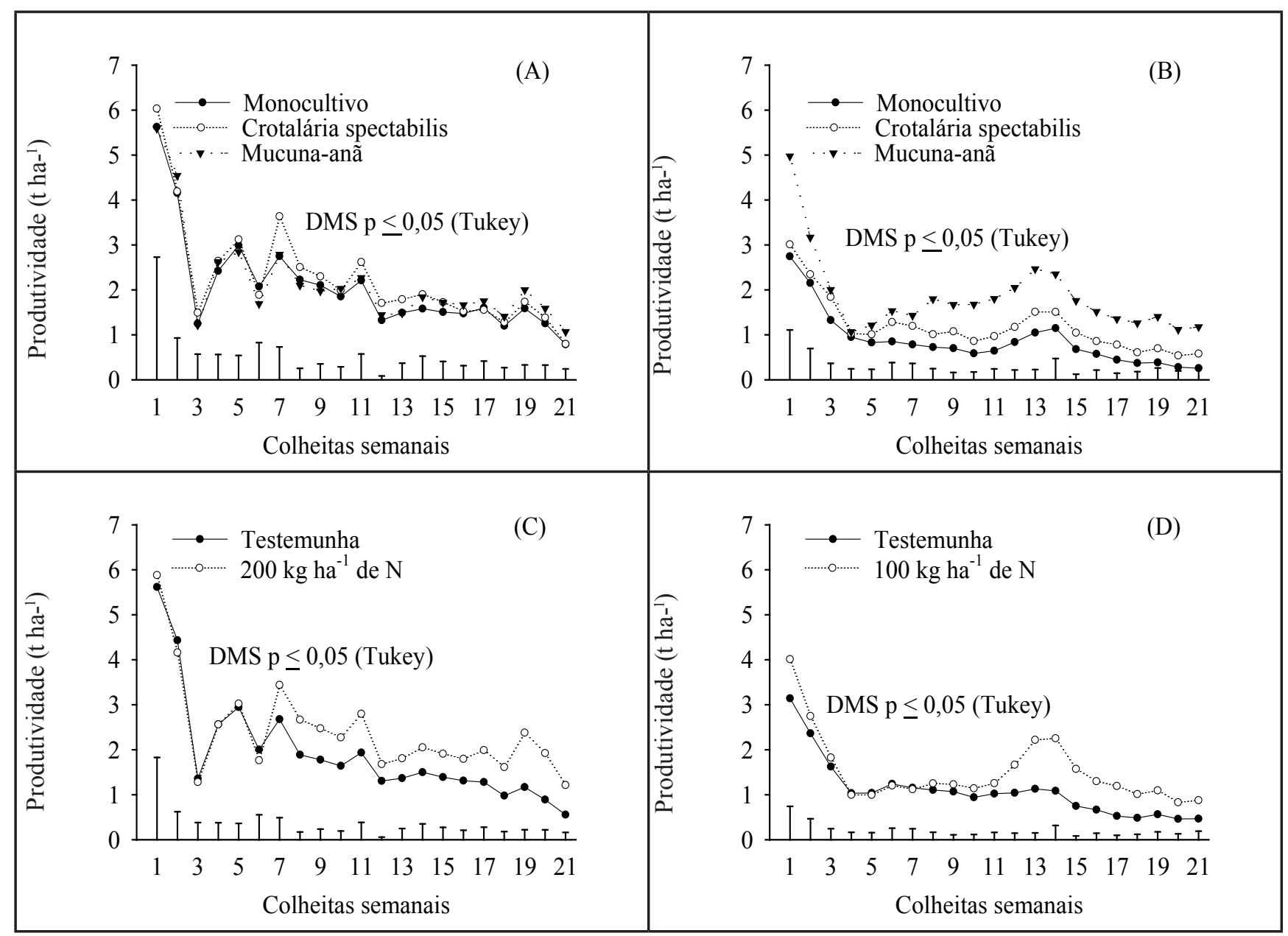

Figura 2. Produtividade comercial de folhas de couve em monocultivo ou consorciada com crotalária spectabilis ou mucuna-anã nos anos

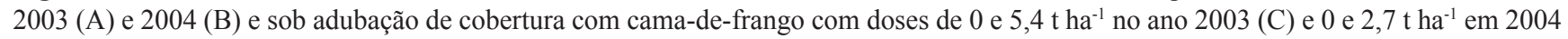
(D) (marketable leaves productivity of collard greens in monoculture or intercropped with showy crotalaria or dwarf velvet bean in 2003 (A) and 2004 (B) and under applications with poultry bed manure in the dose of 0 and of $5.4 \mathrm{t} \mathrm{ha}^{-1}$ in the year 2003 (C) and 0 and $2.7 \mathrm{t}$ ha ${ }^{-1}$ in 2004 (D)). Seropédica, Embrapa Agrobiologia, 2003/2004.

não só foi verificado aumento na produtividade da cultura de quiabeiro em consórcio com crotalária juncea, como também redução de galhas causadas pela infestação de fitonematóides nas raízes (Ribas et al., 2003).

As variações em produtividade no decorrer do ciclo foram proporcionais àquelas relativas ao número de folhas por colheita (Figura 1), nos dois anos de cultivo da couve. A acentuada queda de produção da $1^{\text {a }}$ para a $2^{\text {a }}$ colheitas, provavelmente resultou do período de crescimento de 20 dias decorrido do transplantio até a $1^{\mathrm{a}}$ colheita, ao passo que entre as colheitas subsequentes e consecutivas os intervalos foram semanais.

O estímulo promovido pela adubação de cobertura da couve após a $6^{\mathrm{a}}$ colheita foi mantido até a $12^{\text {a }}$ colheita, excetuando-se a $11^{\text {a }}$ (Figura 1C). A segunda adubação em cobertura, efetuada na $16^{\text {a }}$ colheita, foi suficiente para elevar a taxa de emissão de folhas, permanecendo até o final do primeiro ciclo da couve (Figura 1C). No segundo ciclo, após a $10^{\mathrm{a}}$ colheita, o mesmo efeito foi observado quanto à taxa de emissão de folhas (Figura 1D).

No primeiro ano de cultivo (Figura 2C), a aplicação da primeira dose de cama-de-frango em cobertura, promoveu aumentos de produtividade de 22 a $54 \%$, verificadas a partir da $7^{\text {a }}$ colheita e até completar-se o ciclo da couve. Já a segunda adubação de cobertura, na mesma dose, não acarretou ganho adicional. Em função deste resultado, optou-se pela aplicação única de camade-frango no ensaio do ano seguinte, o que também gerou ganho em produtivi- dade da couve.

Analisando-se os dados em conjunto, observa-se que a emissão de folhas manteve-se estável até o final do experimento ( $21^{\text {a }}$ colheita), nos dois anos de cultivo, enquanto a produtividade mostrou tendência de queda com a idade das plantas, independente da adubação de cobertura. Provavelmente, a elevação da temperatura ambiente limitou o desenvolvimento vegetativo da couve, reduzindo a expansão do limbo foliar e, consequentemente, a produção de massa aérea por unidade de área cultivada. A produtividade da couve teve incrementos de 7 e $110 \%$ com a mucuna-anã e de 14 e $56 \%$ com crotalária spectabilis, em relação aos monocultivos no primeiro e no segundo anos de cultivo, respectivamente (Tabela 1).

Para o milho, os tipos de consórcio 
usados no plantio antecedente da couve não influenciaram o desempenho da cultura (Tabela 1). Esse resultado pode ser decorrente da baixa produção de massa pelas leguminosas, ambas de porte baixo. A cama-de-frango, por sua vez, promoveu aumentos do número de espigas de milho produzidas, o que demonstrou seu efeito residual.

Concluiu-se no estudo da sucessão entre cultivos orgânicos de milho e couve sob plantio direto consorciados com leguminosas, que crotalária spectabilis e mucuna-anã, cultivadas em consórcio com a couve, beneficiaram a couve quanto à produtividade e número de folhas com padrão comercial. $\mathrm{O}$ mesmo estímulo produtivo verificou-se em decorrência da aplicação de camade-frango em cobertura. O pré-cultivo do milho consorciado com leguminosas influenciou a produtividade e a taxa de emissão de folhas pela couve. O uso da cama-de-frango no cultivo de couve propiciou efeito residual positivo quanto ao desenvolvimento vegetativo do milho subsequentemente cultivado, bem como à quantidade das espigas comercializáveis in natura.

\section{AGRADECIMENTOS}

À Capes, pela concessão da bolsa de mestrado a Edmilson Evangelista da Silva e à FAPERJ e CNPq, pelo auxílio financeiro para realização do estudo.

\section{REFERÊNCIAS}

CESAR MNZ; RIBEIRO RLD; PAULA PD; POLIDORO JC; MANERA TC; GUERRA JGM. 2007. Desempenho do pimentão em cultivo orgânico, submetido ao desbaste e consórcio. Horticultura Brasileira 25: 322326.

EMBRAPA. Centro Nacional de Pesquisa de Solos. 1999. Sistema Brasileiro de Classificação de Solos. Rio de Janeiro, 412 p.

ESPINDOLA JAA; GUERRA JGM; PERIN A; TEIXEIRAMG; ALMEIDADL; URQUIAGA S; BUSQUET RNB. 2006. Bananeiras consorciadas com leguminosas herbáceas perenes utilizadas como coberturas vivas. Pesquisa Agropecuária Brasileira 41: 415420.

OLIVEIRA FL; GUERRA JGM; RIBEIRO RLD; ALMEIDA DL; URQUIAGA S; ESPÍNDOLA JAA. 2007. The use of sunn hemp as green manure intercropped with taro. Horticultura Brasileira 25: 556-560.

OLIVEIRA FL; RIBAS RGT; JUNQUEIRA RM; PADOVAN MP; GUERRA JGM; ALMEIDA DL; RIBEIRO RLD. 2003. Uso do pré-cultivo de Crotalaria juncea e de doses crescentes de cama-de-aviário na produção do repolho sob manejo orgânico. Agronomia 37: 60-63.

OLIVEIRA TK; CARVALHO GJ; MORAES RN; JUNIOR PRMJ. 2003. Características agronômicas e produção de fitomassa de milho verde em monocultivo e consorciado com leguminosas. Ciência Agrotécnica 27: 223-227.

PEEL, MC; FINLAYSON BL; McMAHON TA. 2007. Updated world map of the KöppenGeiger climate classification. Hydrology and Earth System Sciences 11: 1633-1644.

PEREIRA AA; HUNGRIA M; FRANCHINI JC; KASCHUK G; CHUEIRE LMO; CAMPO RJ; TORRES E. 2007. Variações qualitativas e quantitativas na microbiota do solo e na fixação biológica do nitrogênio sob diferentes manejos com soja. Revista Brasileira de Ciência do Solo 31: 1397-1412.

PERIN A; SANTOS RHS; URQUIAGA S; GUERRA JGM; CECON PR. 2004. Efeito residual da adubação verde no rendimento de brócolo (Brassica oleraceae L. var. italica) cultivado em rotação de culturas com milho. Ciência Rural 34: 1739-1745.

PERIN A; BERNARDO JT; SANTOS RHS: FREITAS GB. 2007. Desempenho agronômico de milho consorciado com feijão-de-porco em duas épocas de cultivo no sistema orgânico de produção. Ciência e Agrotecnologia 31: 903-908

PONTES KLM. 2001. Avaliação da produção orgânica de tomateiro rasteiro (Lycopersicon esculentum Mill.) em dois sistemas de plantio após pré-cultivo de sorgo consorciado com girassol. Seropédica: UFRRJ. 165p (Tese mestrado).

RIBAS RGT; JUNQUEIRA RM; OLIVEIRA FL; GUERRA JGM; ALMEIDA DL; ALVES BJR; RIBEIRO RLD. 2003. Desempenho do quiabeiro (Abelmoschus esculentus) consorciado com Crotalaria juncea sob manejo orgânico. Agronomia 37: 79-83.

SILVA EE; DE-POLLI H; LOSS A; PEREIRA MG; RIBEIRO RLD; GUERRA JGM. 2009. Matéria orgânica e fertilidade do solo em cultivos consorciados de couve com leguminosas anuais. Revista Ceres 56:93102.

SKORA NETO F. Controle de plantas daninhas através de coberturas verdes consorciadas com milho. 1993. Pesquisa Agropecuária Brasileira 28: 1165-1171.

UFV. 2001. SAEG - Sistema para análise estatística e genética. Versão 8.0, Viçosa: UFV. 150p.

WUTKE EB; VILA JC; PEREIRA JCVNA; ARRUDA FB; SAKAI E; AMBROSANO GMB. 2003. Sucessão de culturas aumenta rendimento do feijoeiro irrigado no Nordeste paulista. O Agronômico 55: 10-13. 